\title{
SECAGEM DE RESÍDUO DE MARACUJÁ EM SECADOR ROTATÓRIO - UMA AVALIAÇÃO EXPERIMENTAL DO COMPORTAMENTO DINÂMICO.
}

\author{
B. D. de MOURA ${ }^{1}$, E. L. de OLIVEIRA ${ }^{1}$, L. V. M. de S. CELESTINO ${ }^{1}$ e J. A. de \\ OLIVEIRA $^{1}$
}

${ }^{1}$ Universidade Federal do Rio Grande do Norte, Departamento de Engenharia Química E-mail para contato: briggidadantas@yahoo.com.br

\begin{abstract}
RESUMO: A crescente atividade industrial de beneficiamento de polpas de frutas é responsável pela geração de uma quantidade significativa de subproduto na forma de resíduos, constituídos basicamente de semente, casca e bagaço da fruta. Tais resíduos ainda são pouco aproveitados e o seu descarte pode conduzir a prejuízos ambientais consideráveis. Portanto, é de grande interesse científico e tecnológico o desenvolvimento de estratégias para agregar valor econômico a estes resíduos. A secagem representa uma alternativa interessante de aproveitamento, podendo viabilizar a produção de material com potencial de aplicação, por exemplo, como ingrediente na formulação de ração animal. Neste trabalho, foi realizado um estudo de secagem do resíduo de maracujá através de um secador rotatório operando com alimentação intermitente do material. Diferentes condições de intermitência e de temperatura do ar de secagem foram estudadas experimentalmente com o objetivo de avaliar o comportamento de resposta na saída do secador dos seguintes parâmetros: a umidade do sólido; a umidade do ar; a temperatura do ar; e a massa produzida cumulativamente ao longo da secagem. A partir dos resultados experimentais foi possível observar que a umidade do sólido variou numa mesma faixa para as três condições de temperatura $\left(75,95\right.$ e $\left.115^{\circ} \mathrm{C}\right)$. Também, foi possível notar o comportamento da umidade e da temperatura do ar na saída do secador como resposta aos efeitos da intermitência na alimentação.
\end{abstract}

\section{INTRODUÇÃO}

O interesse em reaproveitar os resíduos agroindustriais está se tornando cada vez mais crescente (Alexandrino et al., 2007). A aplicação de métodos de conservação, como a secagem, oferece vantagens importantes no tratamento destes resíduos, tais como: manuseio, facilidade de transporte e armazenamento sem perdas significativas.

Para que a secagem seja viável, é imprescindível que ela seja rápida, pouco onerosa e que provoque alterações pouco significativas na qualidade do produto (Figueira, 2010). O secador rotatório pode ser indicado para a secagem de uma grande variedade de materiais. São 
bastante utilizados para a secagem de granulados ou particulados sólidos, devido à sua característica, versatilidade e baixo custo na construção em comparação com outros tipos de secadores (Ajayi e Sheehan, 2012).

Nos secadores rotatórios, o contato entre o gás aquecido e o material dentro do secador pode ser realizado de forma direta ou indireta. O aquecimento direto ocorre quando o material entra em contato direto com o gás aquecido e o indireto ocorre quando o material está no interior de um invólucro, aquecido externamente pelo gás quente. $\mathrm{O}$ gás aquecido pode ser alimentado em contra corrente ou concorrente em relação ao fluxo de material úmido. Geralmente, os secadores rotatórios com fluxo contra corrente ou concorrente possuem suspensores fixados no interior do cilindro para provocar um cascateamento do material e aumentar o contanto do sólido com o gás secante. De acordo com Perry e Green (1999), a profundidade dos suspensores pode variar entre 1/12 e 1/8 em relação ao diâmetro do cilindro.

Os secadores rotatórios possuem uma alta capacidade de processamento, onde sua alimentação pode ser operada de forma contínua. Porém, o objetivo deste trabalho foi realizar um estudo de secagem do resíduo de maracujá através de um secador rotatório operando com alimentação intermitente do material em diferentes condições de intermitência e de temperatura do ar de secagem, visando avaliar seu comportamento dinâmico de resposta.

\section{MATERIAIS E MÉTODOS}

No presente estudo, o resíduo de maracujá foi adquirido da indústria de processamento de polpa de frutas "Delícia da Fruta", localizada no município de Natal/RN.

Os experimentos de secagem com o resíduo de maracujá foram realizados num secador rotatório instalado no Laboratório de Energia Alternativa e Fenômenos de Transporte (LEAFT) do Departamento de Engenharia Química da UFRN.

Na Figura 1, é possível observar a imagem do secador com indicação detalhada do equipamento. Tal secador opera em fluxo concorrente e aquecimento direto, de modo que o ar quente entra em contato com o material no tambor rotatório e ambos se deslocam na mesma direção. O secador possui um tambor cilíndrico levemente inclinado em relação à horizontal, com diâmetro e comprimento de $15 \mathrm{~cm}$ e $60 \mathrm{~cm}$, respectivamente. No interior do tambor, além da fixação de três suspensores radiais com $3 \mathrm{~cm}$ de dimensão, são adicionados inertes de tecnil em forma esférica com diâmetro de $2,5 \mathrm{~cm}$ e densidade de $1,40 \mathrm{~g} / \mathrm{cm}^{3}$, utilizados para revolver o material e melhorar a homogeneização da secagem.

Através do alimentador de rosca, o resíduo de maracujá foi alimentado intermitentemente de três maneiras diferentes: mantendo-se a alimentação ligada (on) por 5 min e desligada (off) por 5, 10 e $15 \mathrm{~min}$. Os experimentos foram conduzidos em condições de temperatura do ar de secagem de $75^{\circ} \mathrm{C}, 95^{\circ} \mathrm{C}$ e $115^{\circ} \mathrm{C}$. O secador é equipado com um sistema de controle de temperatura do ar de secagem na alimentação com confiabilidade de $\pm 1^{\circ} \mathrm{C}$. Além disso, um sistema de aquisição de dados permite o registro temporal das seguintes variáveis: temperatura do ar na entrada e saída do secador, através de termopares do tipo J; e 
umidade do ar na saída do secador, através de um sensor de umidade NOVUS (modelo RHTDM). Inversores de frequiência são utilizados para ajustar a rotação dos motores do alimentador de rosca e do tambor rotatório. Um soprador de ar centrífugo com potência de 1 Hp é usado para alimentar o ar de secagem e um trocador de calor com resistências elétricas é responsável para atuar no aquecimento e controle da temperatura do ar de secagem.

Para cada experimento, a alimentação do material só foi iniciada quando a temperatura do ar na entrada do secador atingiu o setpoint desejado. Após o início da alimentação, a massa de resíduo descarregada na saída do secador foi amostrada (a cada 5 minutos) e pesada cumulativamente. A umidade das amostras coletadas do sólido foi analisada por estufa a $105^{\circ} \mathrm{C}$ durante $24 \mathrm{~h}$.

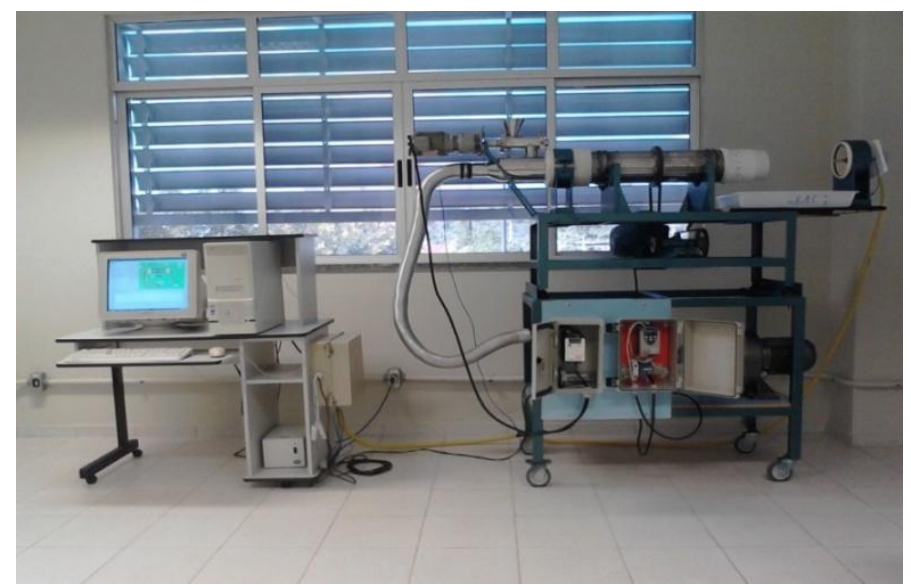

Figura 1 - Secador Rotatório.

Para inferir a produção de material, utilizou-se dos dados da massa produzida cumulativamente. A curva experimental de fração acumulada de massa (Frac) no tempo (t) foi ajustada por regressão não linear à Equação 1, usando o software STATISTICA 7.0 para estimar o parâmetro q. A derivada da Equação 1, que está representada pela Equação 2, permitiu inferir o valor da produção no sistema.

$$
\begin{aligned}
& \operatorname{Frac}(t)=\frac{q^{(t-1)} \cdot\left(q^{2}-2 \cdot q+1\right) \cdot(t \cdot \ln (q)-1+q)}{(\ln (q))^{2}} \\
& \frac{d \operatorname{Frac}}{d t}=(1-q)^{2} \cdot t \cdot q^{(t-1)}
\end{aligned}
$$

\section{RESULTADOS E DISCUSSÃO}

Na Figura 2, estão apresentados os resultados da evolução da umidade do sólido na descarga do secador, em três condições de intermitência de alimentação do material: com alimentação ligada por 5 minutos e desligada por 5 minutos (Figura 2a); com alimentação ligada por 5 minutos e desligada por 10 minutos (Figura 2b); e com alimentação ligada por 5 
minutos e desligada por 15 minutos (Figura 2c). Os experimentos foram realizados nas condições de temperatura do ar de secagem de $75^{\circ} \mathrm{C}, 95^{\circ} \mathrm{C}$ e $115^{\circ} \mathrm{C}$. É possível observar que durante o período de alimentação a umidade do material em base seca ficou entre 0,2 e 0,6 , aproximadamente. Nota-se também que o efeito da temperatura não foi tão significativo sobre a umidade do material. A variação da umidade na faixa observada se deve principalmente à característica da forma de alimentação intermitente. Nos períodos em que a alimentação encontra-se ligada, a umidade do material na descarga tende a aumentar, enquanto nos períodos em que a alimentação encontra-se desligada a umidade do material atinge valores mais baixos. Este efeito pode ser explicado em razão da reumidificação do material em cada etapa de alimentação. No entanto, nota-se que mesmo na intermitência com períodos maiores desligados (Figura 2c) a faixa de umidade encontrada foi similar aos casos onde a intermitência foi aplicada com menores tempos de alimentação desligada. Também pode-se observar que somente após todo o período de alimentação é que as curvas de umidade do material tendem a apresentar um comportamento característico de cinética de secagem, sendo a cinética mais rápida quanto maior é a temperatura do ar de secagem.

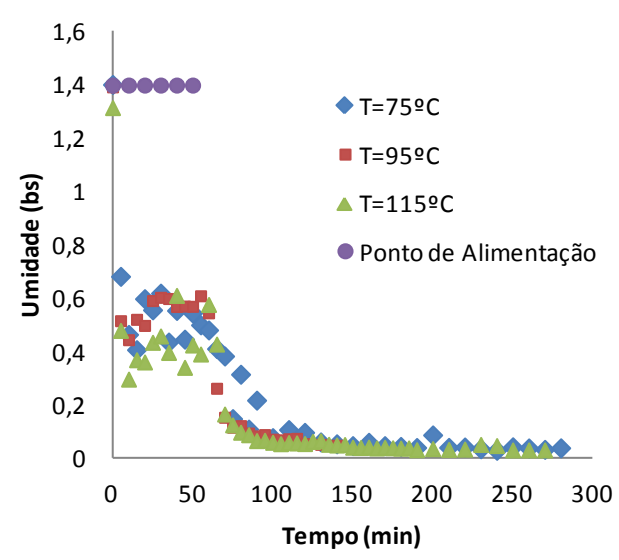

(a)

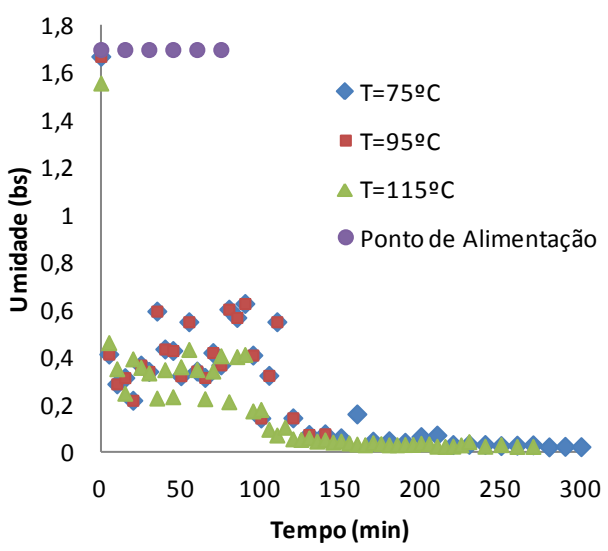

(b)

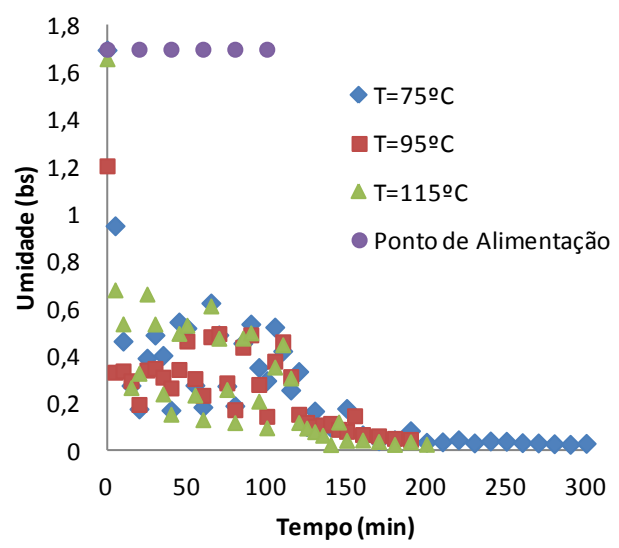

(c)

Figura 2 - Variação da umidade do material - alimentação intermitente com: (a) 5 min ligada e 5 min desligada, (b) 5 min ligada e 10 min desligada e (c) 5 min ligada e 15 min desligada. 
Na Figura 3 são apresentadas as taxas de produção de material na descarga do secador ao longo do tempo. Conforme já mencionado, o material foi amostrado/coletado ao longo do tempo e sua produção quantificada cumulativamente. Para avaliar a sua produção ao longo da secagem, foram feitos os ajustes das curvas acumuladas, calculando-se a derivada da curva de massa acumulada para obter a taxa de produção. É possível notar que as maiores taxas de produção foram obtidas na condição de temperatura de $95^{\circ} \mathrm{C}$.

$\mathrm{Na}$ Tabela 1, estão apresentadas as condições de cada experimento e o valor do parâmetro ajustado para cada curva de massa acumulada no tempo. Para cada experimento foram realizadas seis alimentações de 5 minutos, tendo sido verificado, de acordo com os resultados da Tabela 1, que a vazão de alimentação na intermitência é constante. Para os dois primeiros casos de intermitência tal vazão apresentou pouco desvios nos experimentos. Já no terceiro caso, observou-se uma variação da vazão que foi atribuída a um problema operacional do sistema de alimentação mecânico.

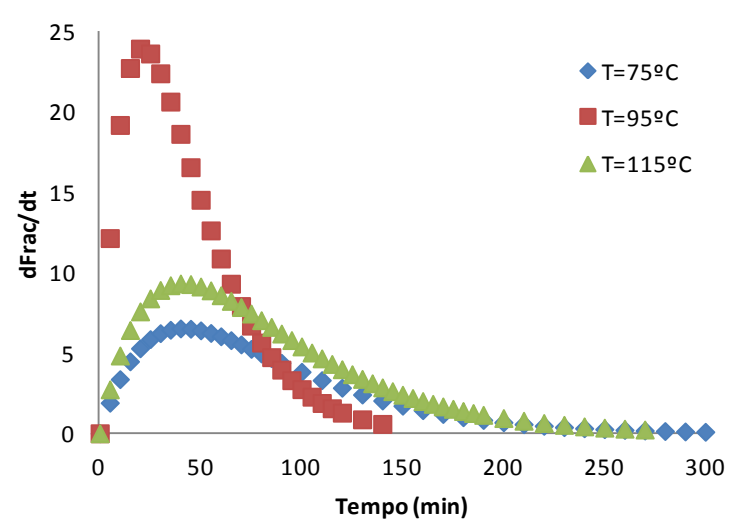

(a)

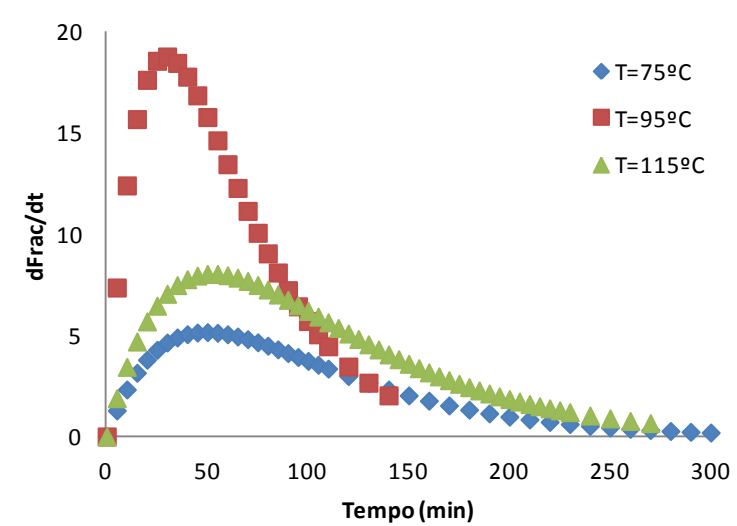

(b)

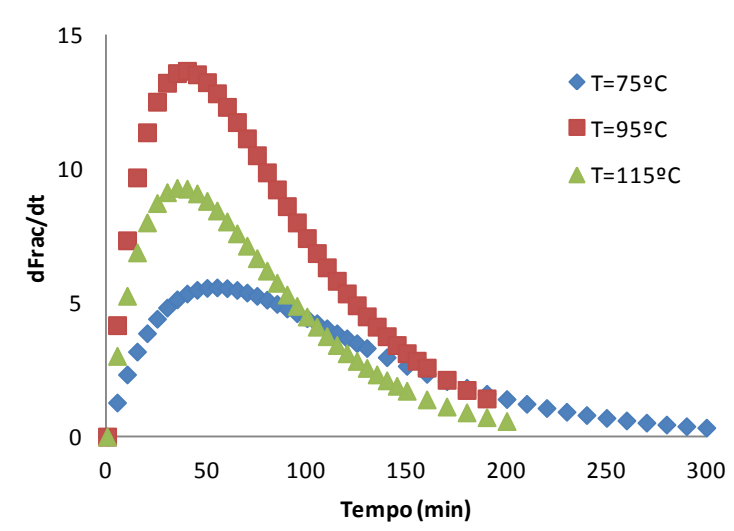

(c)

Figura 3 - Taxa de produção mássica - alimentação intermitente com: (a) 5 min ligada e 5 min desligada, (b) 5 min ligada e 10 min desligada e (c) 5 min ligada e 15 min desligada. 
Tabela 1 - Condições da alimentação intermitente e valores dos parâmetros ajustado para a curva de massas acumuladas (Equação 1)

\begin{tabular}{|c|c|c|c|c|c|c|c|c|c|}
\cline { 2 - 10 } \multicolumn{1}{c|}{} & \multicolumn{3}{c|}{$\begin{array}{c}\text { Alimenta 5 s/ alim. 5 } \\
\text { min. }\end{array}$} & \multicolumn{3}{c|}{ Alimenta 5 s/ alim. 10 } & \multicolumn{3}{c|}{ Alimenta 5 s/ alim. 15 } \\
min. & \multicolumn{4}{c|}{ min. } \\
\hline Temperatura & $75^{\circ} \mathrm{C}$ & $95^{\circ} \mathrm{C}$ & $115^{\circ} \mathrm{C}$ & $75^{\circ} \mathrm{C}$ & $95^{\circ} \mathrm{C}$ & $115^{\circ} \mathrm{C}$ & $75^{\circ} \mathrm{C}$ & $95^{\circ} \mathrm{C}$ & $115^{\circ} \mathrm{C}$ \\
\hline Vazão (g/min) & 76,41 & 75,89 & 76,15 & 85,57 & 87,75 & 87,15 & 76,86 & 93,14 & 64,27 \\
\hline $\mathrm{q}$ & 0,976 & 0,954 & 0,976 & 0,98 & 0,966 & 0,981 & 0,982 & 0,975 & 0,973 \\
\hline $\mathrm{R}^{2}$ & 0,9148 & 0,9845 & 0,9786 & 0,965 & 0,9604 & 0,9918 & 0,9905 & 0,9698 & 0,981 \\
\hline
\end{tabular}

Nas Figuras 4 e 5, apresenta-se a evolução da umidade absoluta e da temperatura do gás na saída do secador, medidas em tempo real durante a secagem. É possível notar o comportamento de resposta dessas variáveis frente à intermitência de alimentação do material no secador. Os resultados demonstram um aumento de umidade do ar, exatamente após a alimentação de material, passando por um máximo e retornando para a condição de mais baixa umidade onde nova alimentação de material era feita. De modo análogo ao comportamento da umidade do gás na saída, também a temperatura do ar na saída apresentou um comportamento de evolução correlacionado à alimentação de material no secador, ocorrendo uma redução na temperatura do ar de saída nos instantes de alimentação do material. Este comportamento dinâmico se deve ao contato do material com o ar quente e aos efeitos de transferência de calor e massa durante a perda de água na secagem, influenciando tanto a umidade quanto a temperatura do ar na saída do secador.

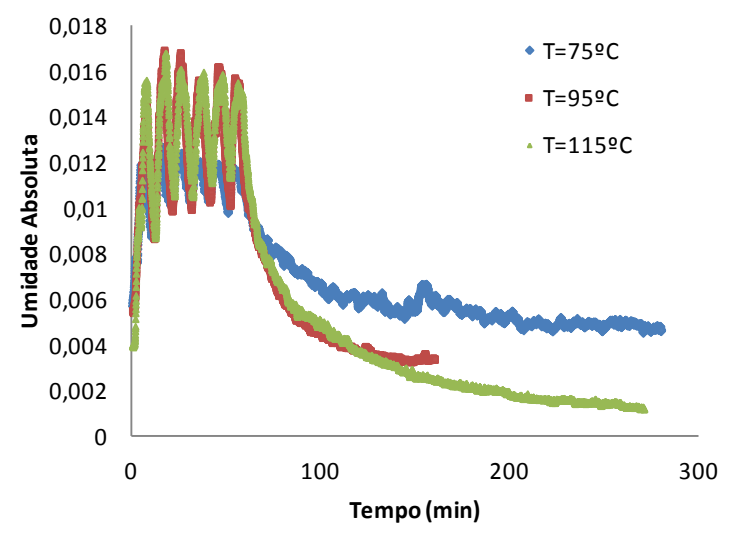

(a)

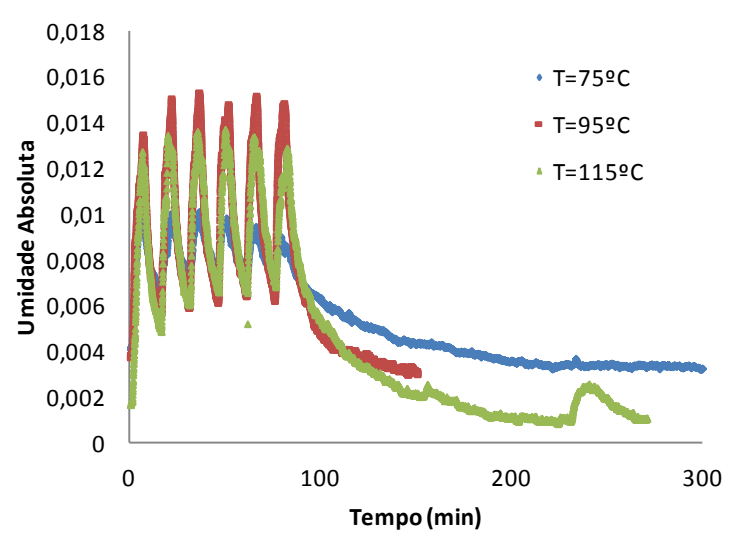

(b) 


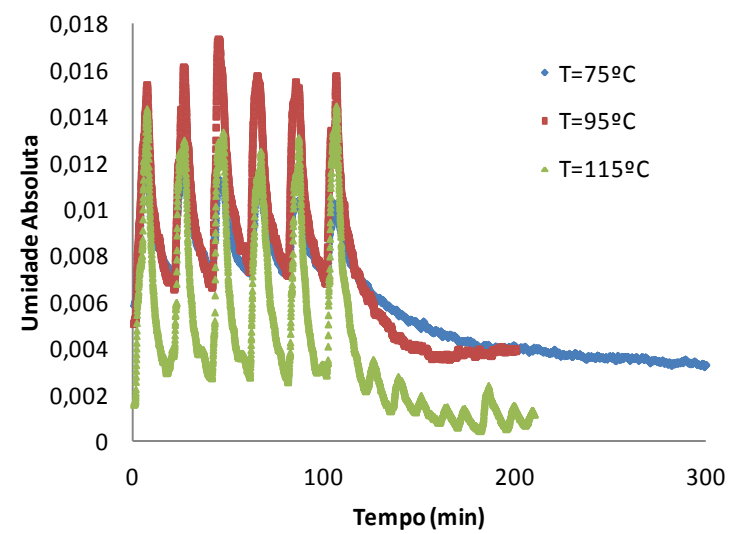

(c)

Figura 4 - Umidade de saída do gás de secagem com o tempo - alimentação intermitente com:

(a) 5 min ligada e 5 min desligada, (b) 5 min ligada e 10 min desligada e (c) 5 min ligada e $15 \mathrm{~min}$ desligada

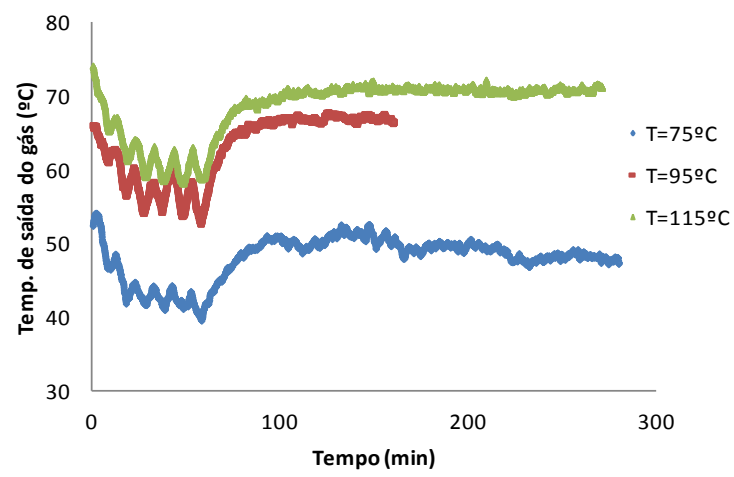

(a)

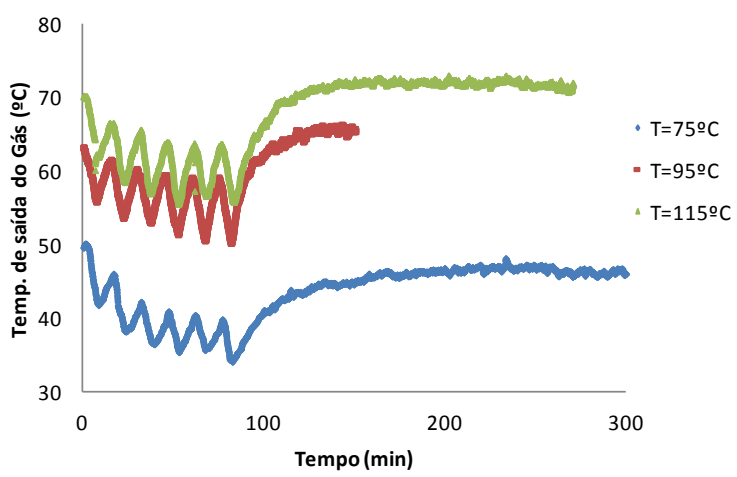

(b)

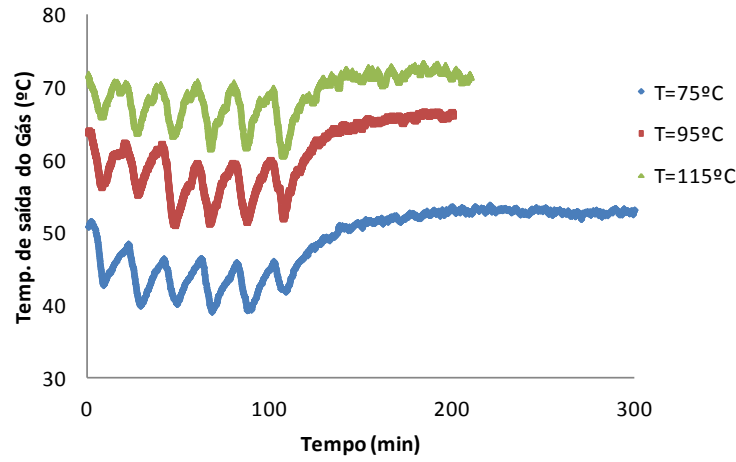

(c)

Figura 5 - Temperatura de saída do gás de secagem com o tempo - alimentação intermitente com: (a) 5 min ligada e 5 min desligada, (b) 5 min ligada e 10 min desligada e (c) 5 min ligada e 15 min desligada. 


\section{CONCLUSÃO}

O comportamento de resposta de um secador rotatório laboratorial foi avaliado dinamicamente na condição de alimentação intermitente de resíduos de maracujá, estudandose diferentes temperaturas do gás de secagem. Foi possível observar que, nas condições de intermitência estudadas, a umidade do material na descarga do secador ficou dentro de uma mesma faixa, independente da condição de temperatura utilizada. Além disso, foi possível observar claramente os efeitos da intermitência de alimentação sobre as variáveis monitoradas em tempo real, tais como: umidade e temperatura do gás na saída. Tais dados serão utilizados no ajuste e avaliação de um modelo matemático fenomenológico que se encontra em desenvolvimento.

\section{REFERÊNCIAS}

AJAYI, O. O.; SHEEHAN, M. E. Design loading of free flowing and cohesive solids in flighted rotary dryers. Chemical Engineering Science, Townsville, Australia, v.73, p.400-411, 2012.

ALEXANDRINO, A. M.; FARIA, H. G.; SOUZA, C. G. M.; PERALTA, R. M. Aproveitamento do resíduo de laranja para a produção de enzimas lignocelulolíticas por Pleurotus ostreatus (Jack:Fr). Ciência e Tecnologia de Alimentos, Campinas, v. 27, n. 2, p. 364-368, 2007.

FIGUEIRA, C. E.; SILVERIO, B. C.; FINZER; J. R. D. Estudo e modelagem da transferência de calor e massa em ensaios de secagem. FAZU em Revista, Uberaba, n.7, p. 145 - 153, 2010.

PERRY, R. H.; GREEN, D. W. Chemical Engineers Handbook. McGraw-Hill, 7 th Cd-ROM, Nova York, Estados Unidos, 1999. 